\title{
Field trial of 2 calcium supplements on early lactation health and production in multiparous Holstein cows
}

\author{
Antonia R. Domino, Helen C. Korzec, and Jessica A. A. McArt ${ }^{1}$ \\ Department of Population Medicine and Diagnostic Sciences, College of Veterinary Medicine, Cornell University, Ithaca, NY 14853
}

\begin{abstract}
Our objectives were to measure serum Ca concentrations in the first $48 \mathrm{~h}$ postpartum in cows supplemented with oral Ca or subcutaneous Ca and nonsupplemented cows and evaluate the effect of these treatments on the incidence of metritis, displaced abomasum, mastitis, and early lactation disease (any of the diseases milk fever, retained placenta, metritis, or displaced abomasum), removal from the herd, pregnancy to first insemination, and average daily milk yield for the first 10 wk of lactation. We conducted 2 experiments on 1 commercial herd in New York State. In experiment 1, multiparous Holstein cows $(\mathrm{n}=30)$ were blocked by parity $(2$ and $\geq 3)$ and sequentially assigned at calving to nontreated control $(\mathrm{CON}, \mathrm{n}=10)$, subcutaneous administration of $500 \mathrm{~mL} 23 \%$ Ca gluconate at calving $(\mathrm{SC}, \mathrm{n}=10)$, or administration of an oral Ca bolus containing $43 \mathrm{~g}$ of calcium at calving and again $12 \mathrm{~h}$ later $(\mathrm{OB}, \mathrm{n}=10)$. Blood was collected before treatment and at $1,2,4,8,12,24$, and $48 \mathrm{~h}$ thereafter for measurement of serum total Ca concentration. In experiment 2, 1,478 multiparous Holstein cows were sequentially assigned by calving date to the same 3 treatments $(\mathrm{CON}, \mathrm{n}=523 ; \mathrm{SC}, \mathrm{n}=480 ; \mathrm{OB}, \mathrm{n}=$ 475). In experiment $1, \mathrm{SC}$ cows had greater $\mathrm{Ca}$ concentrations from 1 through $12 \mathrm{~h}$ post-treatment and OB cows had greater Ca concentrations at 1 and $24 \mathrm{~h}$ post-treatment compared with CON cows. We found no difference in risk of metritis, displaced abomasum, early lactation disease diagnosis, or pregnancy to first insemination among treatments. Treatment with SC or OB had no effect on average daily milk yield compared with $\mathrm{CON}$ cows $(\mathrm{CON}=46.7 \mathrm{~kg}$; $\mathrm{SC}=47.1 \mathrm{~kg}$; OB $=47.0 \mathrm{~kg}$ ). Cows treated with $\mathrm{SC}$ or $\mathrm{OB}$ that had a high relative herd milk rank in the previous lactation were almost half as likely to be diagnosed with mastitis in the first 60 DIM compared with CON cows [risk
\end{abstract}

Received March 17, 2017.

Accepted August 19, 2017.

${ }^{1}$ Corresponding author: jmcart@cornell.edu ratio $\left.(\mathrm{RR})_{\mathrm{SC}}=0.57, \mathrm{RR}_{\mathrm{OB}}=0.54\right]$; however, we found no difference in risk of mastitis among treatments for cows with low relative herd milk rank. Second-parity cows fed a negative prepartum dietary cation-anion difference ration and treated with $\mathrm{SC}$ or $\mathrm{OB}$ were more likely to be removed from the herd than CON cows $\left(\mathrm{RR}_{\mathrm{SC}}=3.91, \mathrm{RR}_{\mathrm{OB}}=4.72\right)$; this difference was not observed in second-parity cows fed a neutral prepartum dietary cation-anion difference ration or in parity $\geq 3$ cows. Although Ca supplementation increased serum $\mathrm{Ca}$, this effect did not greatly improve milk production or health and reproductive outcomes.

Key words: dairy cow, subclinical hypocalcemia, calcium, calcium supplementation

\section{INTRODUCTION}

Dairy cows mobilize a large quantity of Ca around the time of calving to meet the demands of colostrum production and lactation, and this increased $\mathrm{Ca}$ requirement often results in hypocalcemia in the immediate postpartum period. Whereas clinical hypocalcemia (milk fever; MF) affects approximately $5 \%$ of periparturient dairy cows (Goff, 2008), subclinical hypocalcemia (SCH), a low serum concentration within $48 \mathrm{~h}$ of calving, is much more prevalent, affecting up to $50 \%$ of postpartum multiparous cows (Reinhardt et al., 2011). Subclinical hypocalcemia has been associated with hyperketonemia, displaced abomasum (DA), retained placenta, metritis and mastitis, decreased reproductive performance, and decreased milk production (Chapinal et al., 2011, 2012; Martinez et al., 2012). Thus, prevention of SCH represents a sizable opportunity for avoiding other postpartum diseases in dairy cows, thereby improving animal well-being and farm economics.

Testing for SCH is costly and inconvenient, so current efforts have focused on prevention at the herd level rather than identification and treatment of individual animals. The mainstay of prevention is the reduction of the DCAD in prepartum rations (Horst et al., 1997; Lean et al., 2006; Goff, 2008), which has been shown to reduce the incidence of SCH from 50 to $30 \%$ (Joyce et al., 1997). Even at a $30 \%$ incidence, $\mathrm{SCH}$ is estimated 
to cost a 2,000 -cow dairy nearly $\$ 50,000$ annually (Oetzel, 2013).

Additional products marketed for $\mathrm{SCH}$ prevention include oral calcium boluses that contain multiple forms of calcium salts as well as injectable Ca supplements. Oetzel and Miller (2012) demonstrated that use of oral Ca boluses decreased adverse health events for lame cows and increased milk yield in multiparous cows with above-average production in the previous lactation. Miltenburg and colleagues (2016) found that subcutaneous administration of $35 \%$ Ca gluconate and $10 \% \mathrm{Ca}$ glucoheptonate resulted in greater serum Ca concentrations $24 \mathrm{~h}$ post-treatment compared with no treatment, and Amanlou et al. (2016) reported that subcutaneous administration of $40 \% \mathrm{Ca}$ borogluconate resulted in an increased DMI at 1 DIM, a decreased SCC, and a decreased risk for metritis and endometritis compared with nontreated cows. However, to our knowledge, oral and injectable calcium supplements have not been compared in a field trial on a commercial dairy.

We hypothesized that postpartum supplementation with oral Ca boluses or subcutaneous Ca would be superior to no Ca supplementation in the reduction of early lactation disease incidence and herd removal and would increase early lactation milk yield and risk of pregnancy to first AI. Our objectives were to measure serum Ca concentrations during the first $48 \mathrm{~h}$ postpartum in nontreated control cows, cows receiving subcutaneous Ca supplementation immediately postpartum, and cows administered an oral Ca bolus immediately and $12 \mathrm{~h}$ postpartum, and to compare the efficacy of oral or subcutaneous postpartum calcium supplementation with a nontreated control group on early lactation disease incidence, herd removal, early lactation milk yield, and risk of pregnancy to first AI.

\section{MATERIALS AND METHODS}

All procedures were reviewed and approved by the Cornell University Institutional Animal Care and Use Committee (Protocol 2015-0119).

\section{Study Population}

The study was conducted on a Holstein dairy in New York State milking approximately 3,800 cows producing an average of $40 \mathrm{~kg}$ of milk per cow per day during the study period. During the last 3 wk of gestation, cows were housed in 2 close-up freestall pens (pen A and pen B) with a maximum stocking density of $100 \%$. Pen A and pen B were delivered a TMR twice daily with a targeted DCAD level of -10 to $-15 \mathrm{mEq} / 100$ $\mathrm{g}$ of $\mathrm{DM}$ and $0 \mathrm{mEq} / 100 \mathrm{~g}$ of $\mathrm{DM}$, respectively. Cows were monitored for signs of parturition by trained farm employees and moved to straw-bedded maternity pens when entering stage 2 labor. Within $6 \mathrm{~h}$ of parturition, cows were milked with bucket milkers and moved to a freestall fresh pen with a maximum stocking density of $80 \%$, where they were fed a fresh cow TMR delivered twice daily. Cows were milked 3 times per day in a 100-stall rotary parlor (Delaval AB, Tumba, Sweden).

\section{Study Design and Data Collection}

Experiment 1. Between December 7 and 20, 2015, 30 cows in their second-or-greater lactation were enrolled to determine the effect of treatment on serum total Ca concentrations over time. All enrolled cows were fed a targeted prepartum ration DCAD of -10 to -15 $\mathrm{mEq} / 100 \mathrm{~g}$ of DM. Cows were blocked by parity (parity 2 and $\geq 3$ ) and sequentially assigned at calving to 1 of 3 groups: nontreated control $(\mathbf{C O N}, \mathrm{n}=10)$, subcutaneous administration of $500 \mathrm{~mL}$ of $23 \%$ Ca gluconate (10.7 g of Ca; Radix Labs, Eau Claire, WI; SC, n = 10), or oral administration of $2 \mathrm{Ca}$ boluses containing $43 \mathrm{~g}$ of $\mathrm{Ca}$ (Bovikalc, Boehringer Ingelheim, St. Joseph, MO; OB, $\mathrm{n}=10)$. Subcutaneous Ca treatments were administered in a single location behind either shoulder via a simplex set and a 14-gauge needle over a period of approximately $5 \mathrm{~min}$. The first oral Ca bolus was given immediately after calving and the second administered $12 \mathrm{~h}$ after calving. All treatments were administered by the research team. Initial treatment-sequence order was determined using the random number function in Excel (Microsoft, Redmond, WA) and repeated in that order for the remainder of the enrollment period. For all cows, blood was collected from the coccygeal vessels into an evacuated tube without anticoagulant (Becton Dickinson, Franklin Lakes, NJ) immediately before treatment and at $1,2,4,8,12,24$, and $48 \mathrm{~h}$ thereafter; for cows in the OB group, the 12-h blood sample was collected before the second bolus was administered. Samples were allowed to clot at room temperature, transported to Cornell University, and centrifuged within $12 \mathrm{~h}$ of collection for $5 \mathrm{~min}$ at $800 \times g$ and $21^{\circ} \mathrm{C}$. Serum was harvested and frozen at $-80^{\circ} \mathrm{C}$. All serum samples were submitted en masse at the end of the experiment to the New York State Animal Health Diagnostic Center (Ithaca, NY) for quantitative measurement of total Ca concentrations (Hitachi Modular P800, Roche Diagnostics, Indianapolis, IN).

Experiment 2. Between February 7 and August 15, 2016, 1,548 multiparous cows were enrolled in a field trial to determine the effects of oral or subcutaneous Ca supplementation on the incidence of health events in the first 60 DIM, average daily milk yield for the first $10 \mathrm{wk}$ of lactation, and risk of pregnancy to first AI compared with an untreated control group. Cows 
were sequentially assigned by calving date to the same groups as in experiment 1 . Initial day-sequence order was determined using the random number function in Excel and repeated in that order for the remainder of the enrollment period. Farm employees administered all treatments. Subcutaneous Ca treatments were given as described for experiment 1 in a single location behind either shoulder within 30 min of parturition. The first oral Ca bolus was given within 30 min of parturition. The second oral Ca bolus was given after the first morning milking on the $\mathrm{d}$ following calving ( 7 to 32 $\mathrm{h}$ postpartum). To monitor treatment implementation, herd personnel recorded the time of administration of all treatments; these records were observed by the research team at least once weekly throughout the study period. Neither subcutaneous Ca nor oral Ca boluses were administered on the dairy during the study period for purposes other than SCH prevention.

Cases of MF, retained placenta, metritis, DA, and mastitis, as defined by herd protocols, were identified by farm employees and recorded in an electronic recordkeeping program (DairyComp 305, Valley Agricultural Software, Tulare, CA). Disease definitions as described in farm protocols were MF, a down cow within $48 \mathrm{~h}$ postpartum without mastitis or obvious lameness; retained placenta, a cow with presence of a placenta at 2 DIM; metritis, a cow with foul-smelling vaginal discharge and a rectal temperature $\geq 39.7^{\circ} \mathrm{C}$; DA, a cow with a decrease in milk yield and a ping sound on simultaneous auscultation and percussion over the left abdomen in a line extending from the tuber coxae to the olecranon; and mastitis, a cow with altered milk appearance (either garget present or watery consistency) with or without a swollen, painful quarter. Additional data downloaded from the record-keeping program included daily milk weights (sum of thrice-daily milking, subsequently averaged into daily means by week), removal from the herd (died or sold events), outcome of first AI, calving ease, prepartum pen, and previous lactation mature-equivalent milk production.

\section{Analytical Approach}

Experiment 1. Our primary outcome of interest was the difference in mean serum total Ca over the first $48 \mathrm{~h}$ postpartum after allocation to group. The sample size of 10 animals per group was based on an increase in mean serum Ca concentration of at least $0.25 \mathrm{mmol} / \mathrm{L}$ between each treatment and control group, a power of $80 \%$, an acceptable type I error risk of $5 \%$, and a SD of serum Ca concentration at calving of $0.125 \mathrm{mmol} / \mathrm{L}$.

Differences in the proportion of cows in each parity group were analyzed using a Fisher's exact test. Differences in serum $\mathrm{Ca}$ concentration at calving (pretreatment baseline) were analyzed using mixed effects ANOVA with treatment and parity group (parity 2 and $\geq 3$ ) as fixed effects, enrollment block as a random effect, and adjusting for multiple comparisons using Tukey's post hoc test. As a difference in serum $\mathrm{Ca}$ concentration at calving was found among treatments $(\mathrm{CON}=2.02 \pm 0.05 \mathrm{mmol} / \mathrm{L} ; \mathrm{SC}=1.96 \pm$ $0.05 \mathrm{mmol} / \mathrm{L} ; \mathrm{OB}=1.94 \pm 0.05 \mathrm{mmol} / \mathrm{L} ; P=0.006)$, baseline serum Ca concentration was used as a covariate in a repeated-measures ANOVA to analyze Ca concentration over time among treatment. Cow within group was treated as a random effect, with treatment as the effect of interest and baseline Ca concentration, time postpartum, and parity group treated as covariates. Although a univariable association was found between baseline $\mathrm{Ca}$ and parity group $(P=0.02)$, we included the main effect of parity group as a covariate along with baseline $\mathrm{Ca}$ to account for differences in $\mathrm{Ca}$ dynamics over time not described by the baseline $\mathrm{Ca}$ variable alone. Enrollment block was included as a random effect, and the time variable was specified in the REPEATED statement. Results were analyzed using an unstructured covariance, and normality of residuals was tested after each model fit. Variables and their respective interaction terms were considered statistically significant if $P \leq 0.05$. Comparisons of differences in least squares means among treatments over time were controlled for multiplicity using a Bonferroni correction for the number of time points compared. All statistical analyses were performed in SAS (v. 9.4; SAS Institute Inc., Cary, NC). A graph showing the mean Ca concentration of each treatment at each measured time point was created using GraphPad (GraphPad Software Inc., La Jolla, CA).

Experiment 2. Our primary outcome of interest was the difference in average daily milk yield per cow calculated in week averages over the first $10 \mathrm{wk}$ of lactation among treatments. A sample size of 485 cows per group was based on an increase in average milk yield of at least $2 \mathrm{~kg} / \mathrm{d}$ (Oetzel and Miller, 2012) among the treatments, a power of $80 \%$, an acceptable type I error risk of $5 \%$, and a standard deviation of milk yield per week of $7.5 \mathrm{~kg}$, with the resulting number of cows inflated by $10 \%$ to account for enrolled cows excluded from analysis. This number of animals provided us with $80 \%$ power to detect the following differences in secondary outcomes given a type I error risk of $5 \%$ : a 9 and $15 \%$ incidence of metritis, a 1 and $4 \%$ incidence of DA, a 9 and $15 \%$ incidence of mastitis, a 13 and $20 \%$ incidence of combined early lactation health events, a 3 and $7 \%$ incidence of removal from the herd, and a 30 and $39 \%$ incidence of pregnancy to first AI. The incidence risks used for power calculations were based on historical disease data from the study herd. 
Differences in parity group and calving ease $(1=$ unassisted, $2=$ minor assistance, $3=$ major assistance) among treatments were analyzed using a Fisher's exact test. Prepartum pen (pen A or B) and parity group (parity 2 and $\geq 3$ ) were considered as potential confounders because all parity $\geq 3$ cows and $86 \%$ of parity 2 cows were in prepartum pen $\mathrm{A}$, fed a targeted prepartum ration DCAD of -10 to $-15 \mathrm{mEq} / 100 \mathrm{~g}$ of $\mathrm{DM}$, and $14 \%$ of parity 2 cows were in prepartum pen $\mathrm{B}$, fed a targeted prepartum ration DCAD of $0 \mathrm{mEq} / 100$ $\mathrm{g}$ of DM. Parity 2 cows were assigned to prepartum pen by the herd representative responsible for dry cow management based on a subjective assessment of frame size; small-frame cows were assigned to pen B with nulliparous animals. To reduce confounding, a third category was added to the variable parity group (parity group 2A for parity 2 and prepartum pen A, parity group $2 \mathrm{~B}$ for parity 2 and prepartum pen $\mathrm{B}$, parity group 3 for parity $\geq 3$ ). The difference in the 3 -category parity group variable among treatment groups was also tested using a Fisher's exact test. Previous gestation length and previous lactation mature-equivalent milk production (PME305) were analyzed using a univariable ANOVA. The average PME305 of enrolled cows was $13,341 \mathrm{~kg}$, and a relative herd milk rank based on the entire milking herd for each enrolled cow was calculated based on the cow's PME305 divided by the average herd PME305. Cows with a relative herd milk rank $>105 \%$ were categorized as high relative herd milk rank, and cows with a relative herd milk rank $\leq 105 \%$ were classified as low relative herd milk rank (Oetzel and Miller, 2012). The difference in proportion of cows with high or low relative herd milk rank among groups was analyzed using a Fisher's exact test. Potential confounding between relative herd milk rank and parity group was tested via a Cohen's kappa coefficient test and found to be nonimportant $(P=0.29)$.

Differences in average daily milk production across the first $10 \mathrm{wk}$ of lactation among treatments were analyzed using repeated-measures ANOVA. Approximately $5 \%$ of milk weights were misreported due to lost or improperly identified ear tags, and these data were treated as missing values. Cow nested within group was treated as a random effect, with treatment as the variable of interest and week postpartum, parity group, and calving ease included as covariates along with 2-way interaction terms with treatment. The time variable was specified in the REPEATED statement. The model was fitted using backward stepwise elimination of variables considered statistically nonsignificant $(P>0.10)$; treatment group and parity group were considered important variables a priori and included in the model regardless of statistical significance. Results were analyzed using different covariance structures; an unstructured covariance structure was chosen as it produced the lowest Akaike information criterion, a measure of the relative goodness-of-fit. Normality of residuals was tested after each model fit. Differences among least squares means of variable categories retained in the final model were controlled for multiple comparisons using the Tukey post hoc procedure. All statistical analyses were performed in SAS. A graph of the predicted average daily milk yield averaged by week for each treatment was constructed using GraphPad.

Fixed-effects multivariable Poisson regression was used to assess differences among treatments for the risk of pregnancy to first AI and the risk of the following outcomes occurring within 60 DIM: diagnosis of metritis, diagnosis of DA, diagnosis of mastitis, and removal from the herd. In addition, the incidence of cows having at least 1 early lactation disease diagnosis (any of the diseases MF, retained placenta, metritis, or DA) was analyzed. The potential covariates calving ease and relative herd milk rank were tested for univariable associations with each outcome using a Fisher's exact test. Covariates with $P<0.20$ were included in each model along with the variables treatment and parity group along with 2 -way interaction terms with treatment group. The model was fit using backward stepwise elimination of variables considered not statistically significant $(P>0.10)$; treatment and parity group were considered important variables a priori and included in the model regardless of statistical significance. All cows were considered to be at risk for each outcome regardless of time in the herd, except for the outcome of pregnancy to first AI, for which cows were only included if they were inseminated and had a pregnant or open diagnosis. All statistical analyses were performed in SAS.

\section{RESULTS}

\section{Experiment 1}

Figure 1 shows the distribution of serum Ca concentration at calving for each treatment. Median parity number was not different among study groups at 2 (range $=2$ to 4$), 3$ (range $=2$ to 6 ), and 2.5 (range $=2$ to 5) for CON, SC, and OB groups, respectively $(P=1.0)$. The mean time from calving to treatment was $28 \mathrm{~min}$ (range $=10$ to $90 \mathrm{~min}$ ) for subcutaneous $\mathrm{Ca}$ administration, $18 \mathrm{~min}$ (range $=10$ to $30 \mathrm{~min}$ ) for the first oral Ca bolus, and $12 \mathrm{~h} 37 \mathrm{~min}$ for the second bolus (range $=11 \mathrm{~h} 55 \mathrm{~min}$ to $14 \mathrm{~h}$ ). Figure 2 shows the mean serum Ca concentration for each treatment at baseline and 1, 2, 4, 8, 12, 24, and $48 \mathrm{~h}$ post-treatment. The effect of treatment on mean serum Ca concentration was dependent on time point $(P<0.001)$ after 


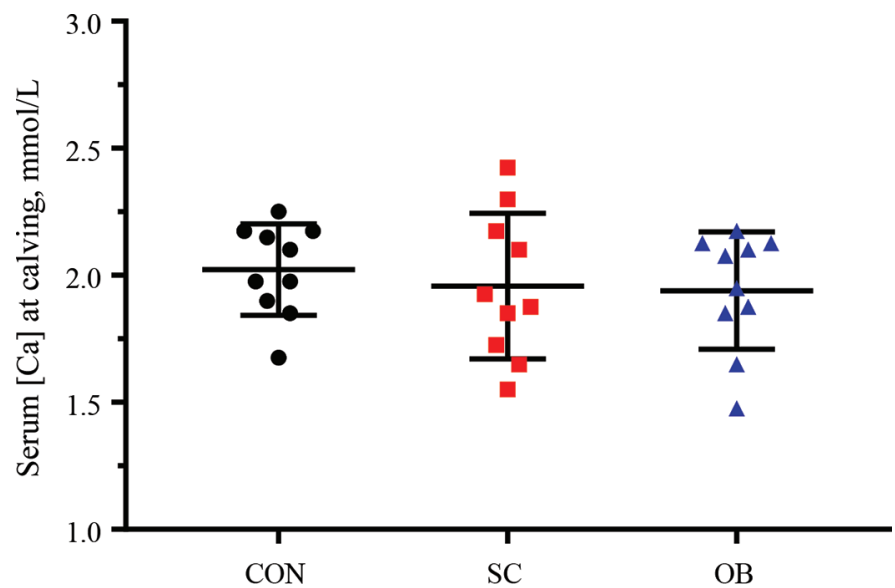

Figure 1. Distribution of serum total Ca concentration of 30 multiparous Holstein cows sampled immediately postpartum that were subsequently assigned to treatments of no treatment control $(\mathrm{CON}, \mathrm{n}$ $=10$ ); subcutaneous administration of $500 \mathrm{~mL}$ of $23 \%$ Ca gluconate immediately after calving ( $\mathrm{SC}, \mathrm{n}=10)$; or oral $\mathrm{Ca}$ bolus $(\mathrm{OB}, \mathrm{n}=$ 10), where cows received 1 bolus containing $43 \mathrm{~g}$ of $\mathrm{Ca}$ immediately after calving followed by a second bolus $12 \mathrm{~h}$ later. Mean and SD are overlaid. Color version available online.

accounting for baseline Ca concentration $(P<0.001)$, parity group $(P=0.13)$, and time point $(P<0.001)$. Cows treated with $\mathrm{SC}$ had greater serum Ca concentra- tions from 1 through $12 \mathrm{~h}$ post-treatment than $\mathrm{CON}$ cows. After adjustment for multiple comparisons, OB cows had greater serum Ca concentrations than CON cows only at the 1 and $24 \mathrm{~h}$ time points. Mean serum Ca concentration across the total 48 -h period was $1.8 \pm$ $0.04,2.1 \pm 0.04$, and $2.0 \pm 0.04 \mathrm{mmol} / \mathrm{L}$ for $\mathrm{CON}, \mathrm{SC}$, and OB cows, respectively.

\section{Experiment 2}

A total of 1,548 multiparous cows were enrolled into experiment 2 at calving. We excluded 70 cows (calving not recorded, $\mathrm{n}=15$; previous gestation length $<260 \mathrm{~d}$, $\mathrm{n}=51$; died or euthanized at calving, $\mathrm{n}=2$; received intravenous calcium in the maternity pen, $\mathrm{n}=2$ ), leaving 1,478 cows in our final analyses $(\mathrm{CON}, \mathrm{n}=523$; $\mathrm{SC}$, $\mathrm{n}=480 ; \mathrm{OB}, \mathrm{n}=475$ ), of which 928 were second parity and 550 were third and greater parity. The distribution of parity group, calving ease, previous gestation length, PME305, and relative herd milk rank by treatment are in Table 1; no difference was found among treatments for any of these variables. The mean time from calving to treatment was $38 \mathrm{~min}$ (range $=5 \mathrm{~min}$ to $3 \mathrm{~h}$ ) for subcutaneous $\mathrm{Ca}$ administration, $37 \mathrm{~min}$ (range $=0$ min to $5 \mathrm{~h} 30 \mathrm{~min}$ ) for the first oral Ca bolus, and $19 \mathrm{~h}$ $12 \mathrm{~min}$ (range $=7 \mathrm{~h}$ to $32 \mathrm{~h}$ ) for the second bolus. No

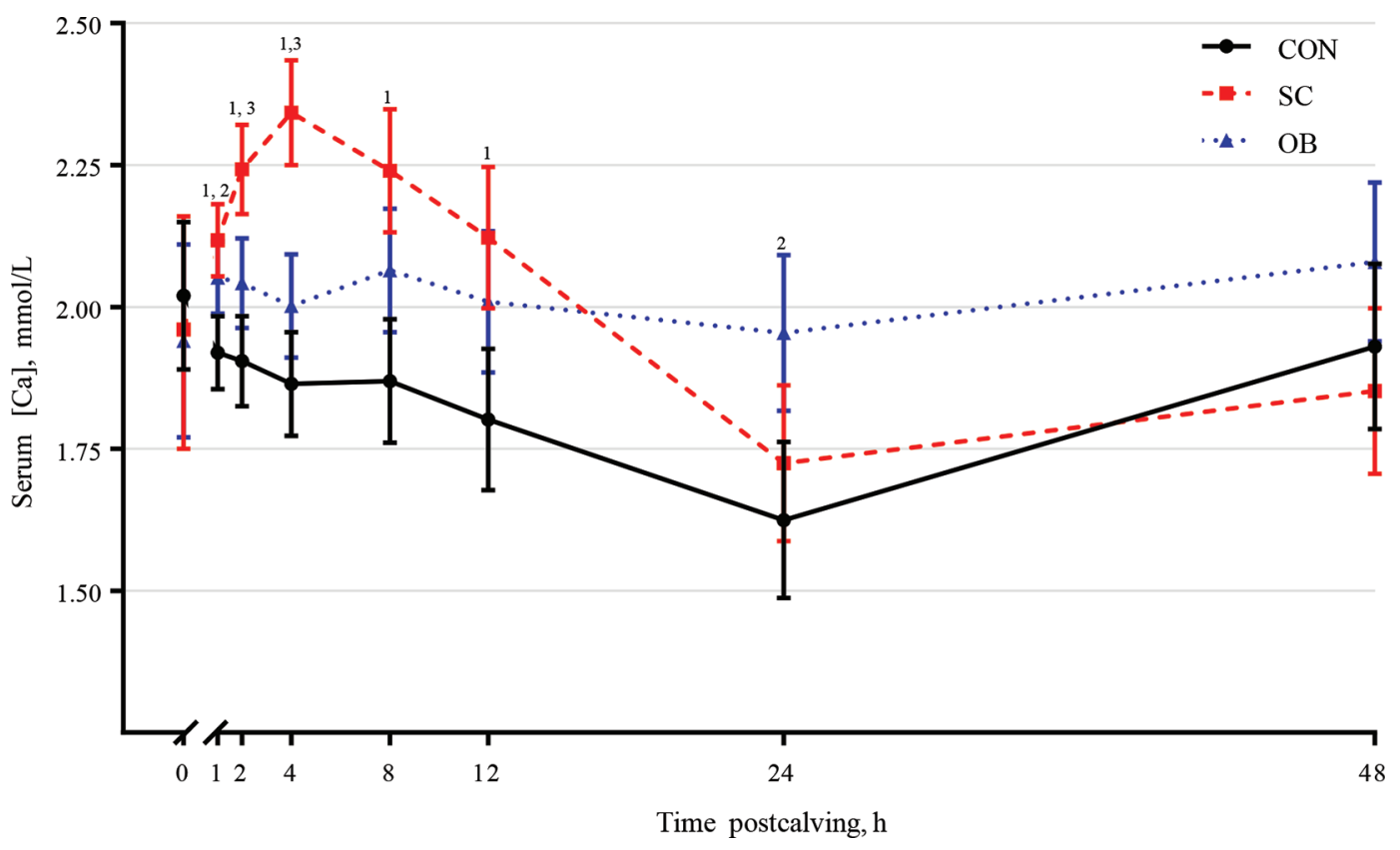

Figure 2. Least squares means and $95 \%$ CI for repeated measurements of serum total Ca concentration at baseline and 1,2,4,8, 12, 24, and $48 \mathrm{~h}$ post-treatment in 30 multiparous Holstein cows sequentially assigned to treatments of no treatment control $(\mathrm{CON}, \mathrm{n}=10) ;$ subcutaneous administration of $500 \mathrm{~mL}$ of $23 \%$ Ca gluconate immediately after calving ( $\mathrm{SC}, \mathrm{n}=10)$; or oral Ca bolus $(\mathrm{OB}, \mathrm{n}=10)$, where cows received 1 bolus containing $43 \mathrm{~g}$ of Ca immediately after calving followed by a second bolus $12 \mathrm{~h}$ later. In addition to the effect of treatment $(P<0.001)$, final model covariates included baseline Ca concentration $(P<0.001)$, parity group (parity 2 and parity $\geq 3, P=0.13)$, time point $(P<0.001)$, and a time point by treatment interaction $(P<0.001)$. Pairwise differences among treatments at each time point, with Bonferroni-corrected $P$ $\leq 0.05$, are marked as ${ }^{1} \mathrm{CON}$ and $\mathrm{SC},{ }^{2} \mathrm{CON}$ and $\mathrm{OB}$, and ${ }^{3} \mathrm{SC}$ and $\mathrm{OB}$. Color version available online. 
Table 1. The distribution of parity group, calving ease, previous gestation length, previous lactation matureequivalent milk production (PME305), and relative herd milk rank for 1,478 Holstein cows randomized by day of calving to groups of no treatment control (CON); subcutaneous administration of $500 \mathrm{~mL}$ of $23 \% \mathrm{Ca}$ gluconate immediately after calving (SC); or oral Ca bolus (OB), where cows received 1 bolus containing $43 \mathrm{~g}$ of $\mathrm{Ca}$ immediately after calving followed by a second bolus 7 to $32 \mathrm{~h}$ later

\begin{tabular}{|c|c|c|c|c|}
\hline Variable & $\mathrm{CON}$ & $\mathrm{SC}$ & $\mathrm{OB}$ & $P$-value ${ }^{1}$ \\
\hline Cows, $\mathrm{n}$ & 523 & 480 & 475 & \\
\hline Parity group, ${ }^{2}$ no. & & & & 0.65 \\
\hline $2 \mathrm{~A}$ & 274 & 257 & 271 & \\
\hline $2 \mathrm{~B}$ & 45 & 43 & 38 & \\
\hline 3 & 204 & 180 & 166 & \\
\hline Calving ease, no. & & & & 0.25 \\
\hline 1 & 408 & 380 & 374 & \\
\hline 2 & 12 & 7 & 13 & \\
\hline 3 & 13 & 5 & 6 & \\
\hline Previous gestation length, ${ }^{3} \mathrm{~d}$ & $276(5)$ & $276(5)$ & $276(4)$ & 0.58 \\
\hline PME $305,{ }^{3} \mathrm{~kg}$ & $13,277(2,058)$ & $13,459(2,143)$ & $13,420(2,123)$ & 0.63 \\
\hline Relative herd milk rank ${ }^{4}$ no. & & & & 0.39 \\
\hline High & 188 & 190 & 188 & \\
\hline Low & 335 & 290 & 287 & \\
\hline
\end{tabular}

${ }^{1} P$-values are based on Fisher's exact tests for parity group, calving ease, and relative herd rank and univariable ANOVA for previous gestation length and PME305.

${ }^{2}$ Parity group: parity group $2 \mathrm{~A}$ for parity $=2$ and a targeted prepartum ration DCAD of -10 to $-15 \mathrm{mEq} / 100$ $\mathrm{g}$ of DM, parity group 2B for parity $=2$ and a targeted prepartum ration DCAD of $0 \mathrm{mEq} / 100 \mathrm{~g}$ of $\mathrm{DM}$, parity group 3 for parity $\geq 3$ and a targeted prepartum ration DCAD of -10 to $-15 \mathrm{mEq} / 100 \mathrm{~g}$.

${ }^{3}$ Mean (SD).

${ }^{4}$ Relative herd milk rank: calculated for each cow based on the PME305 divided by the herd average PME305, with cows with a relative herd rank $>105$ or $\leq 105 \%$ classified as high or low, respectively.

adverse effects were reported for cow receiving $\mathrm{SC}$ or OB treatment.

\section{Effect of Treatment on Milk Yield}

We found no difference in average milk yield among treatments $(P=0.64)$, and average daily milk yield during the first $10 \mathrm{wk}$ of lactation was $46.7 \pm 0.4,47.1$ \pm 0.4 , and $47.0 \pm 0.4 \mathrm{~kg}$ for the $\mathrm{CON}, \mathrm{SC}$, and $\mathrm{OB}$ groups, respectively, after controlling for parity group $(P=0.15)$ and week of lactation $(P<0.001$; Figure 3$)$.

\section{Effect of Treatment on Event Outcomes}

The effect of treatment, incidence of health outcomes and pregnancy to first AI by group, and risk ratio (RR) contrasts from final multivariable Poisson regression models are in Table 2. We found no difference in the risk of cows diagnosed with metritis among treatment $(P=0.21)$ after accounting for parity group $(P=0.13)$ and relative herd milk rank $(P=0.007)$. Cows with a high relative herd milk rank were less likely to be diagnosed with metritis than cows with a low relative herd milk rank $(\mathrm{RR}=0.61,95 \% \mathrm{CI}=0.42$ to 0.89$)$. Similarly, we observed no difference in the risk of cows diagnosed with a DA among groups $(P=0.51)$ after accounting for parity group $(P<0.001)$. Cows in parity group 3 were more likely to develop a DA than cows in parity group $2 \mathrm{~A}(\mathrm{RR}=5.45,95 \% \mathrm{CI}=1.99$ to 14.96$)$; cows in parity group $2 \mathrm{~B}$ were no more likely to develop a DA than cows in parity group $2 \mathrm{~A}(\mathrm{RR}=1.26,95 \%$ $\mathrm{CI}=0.14$ to 11.38$)$.

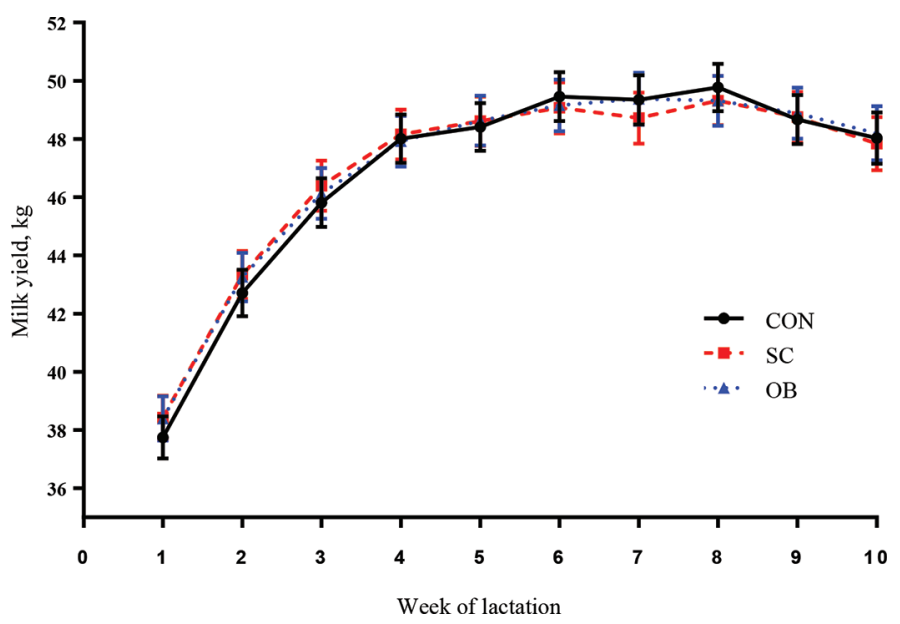

Figure 3. Least squares means and 95\% CI for predicted average daily milk yield averaged by week for the first 10 wk of lactation for 1,478 Holstein multiparous cows assigned by day of calving to immediate postpartum treatments of no treatment control $(\mathrm{CON}, \mathrm{n}=523)$; subcutaneous administration of $500 \mathrm{~mL}$ of $23 \%$ Ca gluconate immediately after calving ( $\mathrm{SC}, \mathrm{n}=480)$; or oral Ca bolus ( $\mathrm{OB}, \mathrm{n}=475)$, where cows received 1 bolus containing $43 \mathrm{~g}$ of Ca immediately after calving followed by a second bolus 7 to $32 \mathrm{~h}$ later. There was no effect of treatment on average daily milk yield $(P=0.64)$ after controlling for parity group $(P=0.15)$ and week of lactation $(P<0.001)$. Color version available online. 
POSTPARTUM CALCIUM SUPPLEMENTATION

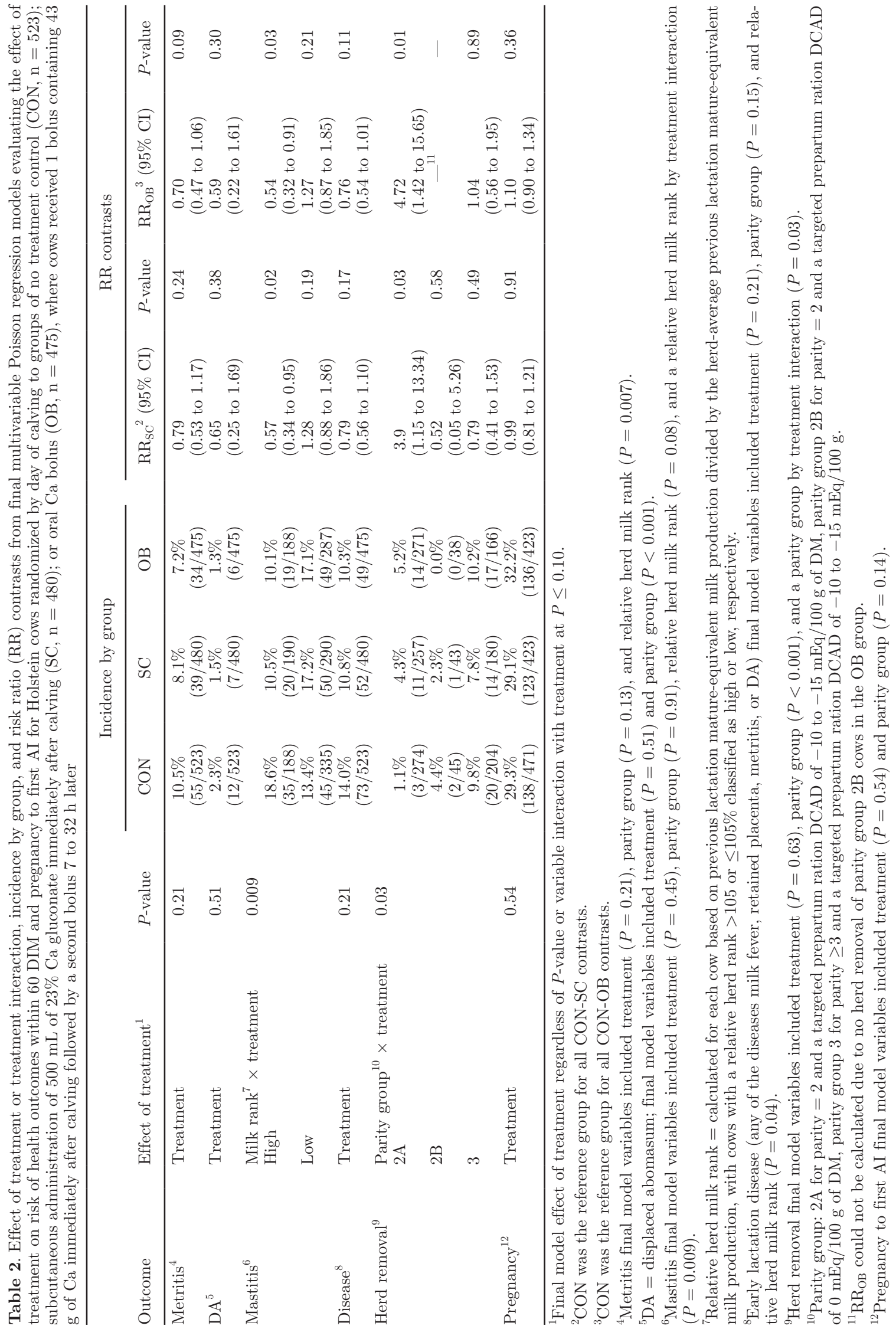


The effect of treatment on the risk of mastitis diagnosis was dependent on relative herd milk rank $(P=$ $0.009)$ after controlling for parity group $(P=0.91)$. For cows with a high relative herd milk rank, those treated with SC were $43 \%$ less likely to be diagnosed with mastitis as CON cows, and those treated with OB were $46 \%$ less likely to be diagnosed with mastitis in the first 60 DIM as CON cows. We noted no difference in mastitis risk among treatment for cows with a low relative herd milk rank.

The incidence of $\mathrm{MF}(\mathrm{CON}=0.2 \%, \mathrm{SC}=0.0 \%, \mathrm{OB}$ $=0.6 \%)$ and retained placenta $(\mathrm{CON}=5.2 \%, \mathrm{SC}=$ $4.2 \%, \mathrm{OB}=4.0 \%$ ) combined with the incidences for metritis and DA produced an incidence of early lactation disease of 14.0, 10.8, and $10.3 \%$ for CON, SC, and OB treatment, respectively. The combined risk of cows diagnosed with MF, retained placenta, metritis, or DA within the first 60 DIM did not differ among treatment $(P=0.21)$ after accounting for parity group $(P=0.15)$ and relative herd milk rank $(P=0.04)$. Cows with high relative herd milk rank were less likely to be diagnosed with 1 or more of the early lactation diseases than cows with low relative herd milk rank $(\mathrm{RR}=0.73,95 \% \mathrm{CI}$ $=0.53$ to 0.99 ).

The effect of treatment on the risk of herd removal was dependent on parity group $(P=0.03)$. For parity $2 \mathrm{~A}$ cows, being treated with $\mathrm{SC}$ or $\mathrm{OB}$ increased the risk of removal compared with CON cows (Table 2). As the parity $2 \mathrm{~B}-\mathrm{OB}$ group did not have any cows removed from the herd in the first $60 \mathrm{DIM}$, an RR was unable to be calculated for the CON-OB contrast; however, as only 3 of 126 cows in this group were removed from the herd during the study, it is unlikely that this difference is important. We found no difference in the risk of removal among $\mathrm{SC}$ or $\mathrm{OB}$ cows compared with $\mathrm{CON}$ cows for parity group 3 .

An outcome of pregnancy to first AI was recorded for 1,317 of the enrolled cows. We observed no difference among treatments in the number of cows missing a recorded outcome of pregnancy to first insemination $(P$ $=0.71)$. The risk of pregnancy to first AI did not differ among groups $(P=0.54)$ after accounting for parity group $(P=0.14)$.

\section{DISCUSSION}

Our study was designed to determine the effect of oral or subcutaneous $\mathrm{Ca}$ supplementation on serum total $\mathrm{Ca}$ concentration in the first $48 \mathrm{~h}$ after parturition compared with nontreated cows and to evaluate the effect of $\mathrm{Ca}$ supplementation on the risk of early lactation disease and herd removal, pregnancy to first $\mathrm{AI}$, and milk production. Both SC and $\mathrm{OB}$ treatments increased serum $\mathrm{Ca}$ concentration immediately after treatment. As expected, the effect of SC was a large but short-lived increase in serum $\mathrm{Ca}$ concentration; mean Ca concentration was greater for SC cows than CON cows from 1 through $12 \mathrm{~h}$ post-treatment, but reached a comparable nadir at the 24-h measurement and remained low at the 48-h measurement. A similar but more pronounced spike in serum Ca concentration and subsequent rebound hypocalcemia was shown by Blanc et al. (2014) when administering $500 \mathrm{~mL}$ of $23 \%$ calcium gluconate intravenously to nonrecumbent cows; this rebound hypocalcemia lasted through the final measurement at $48 \mathrm{~h}$ after treatment. It is possible that the transitory increase in serum $\mathrm{Ca}$ after administration of subcutaneous $\mathrm{Ca}$ does not reach the physiological threshold necessary to interfere with homeostatic mechanisms associated with return to a eucalcemic state, as appeared to occur with intravenous administration. Conversely, although OB treatment produced an increase in Ca concentration over that of CON cows only at 1 and $24 \mathrm{~h}$ post-treatment, the effect of OB treatment was evident at the 24-h time point, when Ca concentrations failed to drop to the nadir seen in the other 2 treatments. Given the small sample size in this part of our study, we found it interesting that OB-treated cows had relatively consistent serum Ca concentrations over the entire 48-h measurement period; this same finding for $\mathrm{OB}$ treatment was described by Blanc et al. (2014).

Despite the differences in serum Ca concentration among treatments in experiment 1 , very few differences in disease incidence, milk production, or reproduction outcomes were found in experiment 2 when the treatments were administered to a much larger number of cows. Although the number of cows enrolled into our study provided enough power to adequately determine there was no difference in average daily milk yield for the first $10 \mathrm{wk}$ of lactation, our sample size may not have been large enough to detect differences among treatments in some of the measure diseases (i.e., MF, retained placenta, metritis, or DA) or pregnancy to first AI. Treatment effects were only found in mastitis diagnosis and herd removal in the first 60 DIM, and for both these outcomes only a subset of animals were affected.

We found that cows with a high relative herd milk rank, those with a PME305 over 5\% greater than the herd average PME305 that received either SC or OB were almost half as likely as nonsupplemented cows to be diagnosed with mastitis in the first 60 DIM. Similar results regarding the benefit of postpartum Ca supplementation in cows with a high relative herd milk rank have been shown by Oetzel and Miller (2012), where high-relative herd milk rank cows treated with oral $\mathrm{Ca}$ boluses produced $2.9 \mathrm{~kg}$ more milk at first DHIA test 
than high-relative herd milk rank cows not administered postpartum Ca supplementation. Martinez et al. (2016b) found similar results with increased doses of oral Ca boluses, in that supplemented cows with high herd mean PME305 yielded 0.8 to $2.7 \mathrm{~kg}$ more milk per day than cows not supplemented with high herd mean PME305. In addition to cows with a high relative herd milk rank, Oetzel and Miller (2012) also found that lame cows benefited from Ca supplementation by reducing the number of negative health events in early lactation; however, we did not evaluate locomotion score in our study. Target group Ca supplementation strategies have been found to be cost-effective (McArt and Oetzel, 2015); however, the overall economic benefit to producers was dependent on herd lameness prevalence and average milk yield at first DHIA test.

Interestingly, we found that parity $2 \mathrm{~A}$ cows (parity 2 cows fed a prepartum ration targeting a DCAD of -10 to $-15 \mathrm{mEq} / 100 \mathrm{~g}$ of $\mathrm{DM}$ ) had a greater risk of herd removal in the first 60 DIM if they received either SC or OB supplementation than nonsupplemented parity group $2 \mathrm{~A}$ cows. As the cows in parity group $2 \mathrm{~A}$ were on a negative DCAD diet prepartum, it is plausible that these cows had improved physiological adaptation to the normal decline in serum Ca concentration postpartum, as feeding a negative DCAD diet has been shown to reduce SCH (Joyce et al., 1997); however, the administration of additional Ca may have interfered with this inherent adaptation and proved detrimental. This effect of treatment on herd removal was not found in parity $2 \mathrm{~B}$ cows (parity 2 cows fed a prepartum ration targeting a DCAD of $0 \mathrm{mEq} / 100 \mathrm{~g}$ of $\mathrm{DM}$ ) nor in parity $\geq 3$ cows. As parity 2 cows were assigned to prepartum pen based on frame size, only $27 \%$ of cows in parity group $2 \mathrm{~B}$ were of high relative herd milk rank, whereas $41.3 \%$ of cows in parity group $2 \mathrm{~A}$ were of the same rank. It is possible that postpartum serum blood Ca concentration in parity group $2 \mathrm{~B}$ cows was, on average, higher than that of parity group 2A cows, and minimal homeostatic regulation was required to maintain eucalcemia; thus, additional Ca supplementation was not detrimental. Although $\mathrm{Ca}$ status and regulation throughout early lactation may explain the difference in herd removal incidence seen among parity groups (as parity group was not an important contributor to the effect of postpartum Ca supplementation on milk yield, disease incidence, or pregnancy to first AI), it is difficult to explain the reason of herd removal behind this finding. Our results, in addition to the negative findings of Martinez et al. (2016a,b), when primiparous cows were repeatedly supplemented with $\mathrm{Ca}$ postpartum over multiple days, suggest that more research is needed to evaluate $\mathrm{Ca}$ homeostasis and response to $\mathrm{Ca}$ supplementation in younger cows.
Similar to our lack of treatment effect on metritis, DA, early lactation disease, and pregnancy to first AI outcomes, Miltenburg et al. (2016) reported no effect of a postpartum 2-dose subcutaneous Ca supplementation regimen on the risk of culling or early lactation diseases, early lactation milk yield, or reproductive performance in 984 cows across 7 farms in Canada. In a comparable study by Amanlou et al. (2016) in 375 cows in 1 Iranian herd, cows given 2 infusions of subcutaneous Ca within the first $18 \mathrm{~h}$ postpartum were less likely to develop metritis and clinical and subclinical endometritis than nontreated control cows. Although our study evaluated the effect of postpartum Ca supplementation in 1,478 cows, it was limited to enrollment on a single dairy farm. Given the inconsistency of reported effects of postpartum Ca supplementation and the variety of nutritional and management strategies available for prevention of $\mathrm{SCH}$, it is likely that the success of $\mathrm{Ca}$ supplementation might vary depending on the herd in which it is used.

\section{CONCLUSIONS}

Although our results show that subcutaneous Ca supplementation substantially raised serum Ca concentrations for $12 \mathrm{~h}$ and that oral Ca supplementation produced a more modest but prolonged increase at 1 and $24 \mathrm{~h}$ over nonsupplemented cows, these effects on serum blood $\mathrm{Ca}$ were not enough to create a considerable improvement in health outcomes, milk production, or reproductive success. Though beneficial effects of Ca supplementation were seen in high-relative herd milk rank cows through the reduction of mastitis cases, $\mathrm{Ca}$ supplementation also increased herd removal in subset of second-parity cows. Until methods of on-farm SCH detection become more accurate and economical, providing targeted $\mathrm{Ca}$ supplementation may have greater benefits than whole-herd supplementation.

\section{ACKNOWLEDGMENTS}

Boehringer Ingelheim Vetmedica Inc. (St. Joseph, MO) provided financial support for this study. We are grateful to Nicholas Ledesma (Ithaca, NY) for his assistance with blood collection, sample processing, and treatment administration, as well as to the commercial dairy and its calving crew and management team whose cooperation and participation made this work possible.

\section{REFERENCES}

Amanlou, H., A. P. Akbari, N. E. Farsuni, and N. Silva-Del-Río. 2016. Effects of subcutaneous calcium administration at calving on mineral status, health, and production of Holstein cows. J. Dairy Sci. 99:9199-9210. https://doi.org/10.3168/jds.2015-10844. 
Blanc, C. D., M. Van der List, S. S. Aly, H. A. Rossow, and N. Silvadel-Rio. 2014. Blood calcium dynamics after prophylactic treatment of subclinical hypocalcemia with oral or intravenous calcium. J. Dairy Sci. 97:6901-6906. https://doi.org/10.3168/jds.2014-7927.

Chapinal, N., M. Carson, T. F. Duffield, M. Capel, S. Godden, M. Overton, J. E. P. Santos, and S. J. LeBlanc. 2011. The association of serum metabolites with clinical disease during the transition period. J. Dairy Sci. 94:4897-4903. https://doi.org/10.3168/jds $.2010-4075$.

Chapinal, N., M. E. Carson, S. J. LeBlanc, K. E. Leslie, S. Godden, M. Capel, J. E. P. Santos, M. W. Overton, and T. F. Duffield. 2012 The association of serum metabolites in the transition period with milk production and early-lactation reproductive performance. J. Dairy Sci. 95:1301-1309. https://doi.org/10.3168/jds.2011-4724.

Goff, J. P. 2008. The monitoring, prevention, and treatment of milk fever and subclinical hypocalcemia in dairy cows. Vet. J. 176:50-57. https://doi.org/10.1016/j.tvjl.2007.12.020.

Horst, R. L., J. P. Goff, T. A. Reinhardt, and D. R. Buxton. 1997. Strategies for preventing milk fever in dairy cattle. J. Dairy Sci. 80:1269-1280. http://dx.doi.org/https://doi.org/10.3168/jds .S0022-0302(97)76056-9.

Joyce, P. W., W. K. Sanchez, and J. P. Goff. 1997. Effect of anionic salts in prepartum diets based on alfalfa. J. Dairy Sci. 80:28662875. https://doi.org/10.3168/jds.S0022-0302(97)76251-9.

Lean, I. J., P. J. DeGaris, D. M. McNeil, and E. Block. 2006. Hypocalcemia in dairy cows: Meta-analysis and dietary cation anion difference theory revisited. J. Dairy Sci. 89:669-684. http://dx.doi .org/https://doi.org/10.3168/jds.S0022-0302(06)72130-0.

Martinez, N., C. A. Risco, F. S. Lima, R. S. Bisinotto, L. F. Greco, E. S. Ribeiro, F. Maunsell, K. Galvao, and J. E. Santos. 2012. Evaluation of peripartal calcium status, energetic profile, and neutrophil function in dairy cows at low or high risk of developing uterine disease. J. Dairy Sci. 95:7158-7172.

Martinez, N., L. D. P. Sinedino, R. S. Bisinotto, R. Daetz, C. Lopera, C. A. Risco, K. N. Galvão, W. W. Thatcher, and J. E. P. Santos 2016a. Effects of oral calcium supplementation on mineral and acid-base status, energy metabolites, and health of postpartum dairy cows. J. Dairy Sci. 99:8397-8416. https://doi.org/10.3168/ jds.2015-10527.

Martinez, N., L. D. P. Sinedino, R. S. Bisinotto, R. Daetz, C. A. Risco, K. N. Galvão, W. W. Thatcher, and J. E. P. Santos. 2016b. Effects of oral calcium supplementation on productive and reproductive performance in Holstein cows. J. Dairy Sci. 99:8417-8430. https:/ doi.org/10.3168/jds.2015-10529.

McArt, J. A. A., and G. R. Oetzel. 2015. A stochastic estimate of the economic impact of oral calcium supplementation in postparturient dairy cows. J. Dairy Sci. 98:7408-7418. https://doi.org/10 $.3168 /$ jds.2015-9479.

Miltenburg, C. L. T. F Duffield, D. Bienzle, E. L Scholtz, and S. J. LeBlanc. 2016. Randomized clinical trial of a calcium supplement for improvement of health in dairy cows in early lactation. J. Dairy Sci. 99:6550-6562. https://doi.org/10.3168/jds.2016-10961.

Oetzel, G. R. 2013. Oral calcium supplementation in peripartum dairy cows. Vet. Clin. North Am. Food Anim. Pract. 29:447-455. https://doi.org/10.1016/j.cvfa.2013.03.006.

Oetzel, G. R., and B. E. Miller. 2012. Effect of oral calcium bolus supplementation on early-lactation health and milk yield in commercial dairy herds. J. Dairy Sci. 95:7051-7065. https://doi.org/ 10.3168/jds.2012-5510.

Reinhardt, T. A., J. D. Lippolis, B. J. McCluskey, J. P. Goff, and R. L. Horst. 2011. Prevalence of subclinical hypocalcemia in dairy herds. Vet. J. 188:122-124. https://doi.org/10.1016/j.tvjl.2010.03.025. 